NF- $\kappa \mathrm{B}$ target genes. The expression of interleukin- $1 \alpha$ (IL-1 $\alpha), \mathrm{IL}-1 \beta$ and COX2, which are normally induced by LPS-mediated activation of macrophages, was inhibited by SB202190. Interestingly, treatment with LT inhibited the expression of the same genes.

The authors conclude that, through phosphorylation of an asyet-unidentified target, $\mathrm{p} 38$ synergizes with NF- $\kappa B$ to induce the expression of anti-apoptotic genes in macrophages. By inhibiting the activation of $\mathrm{p} 38, B$. anthracis changes a macrophage activation signal into a signal for cell death, so enabling the bacterium to evade the innate immune response. ORIGINAL RESEARCH PAPER Park, J. M. et al. Macrophage apoptosis by anthrax lethal factors through p38 MAP kinase inhibition. Science 297, 2048-2051 (2002)

FURTHER READING Guidi-Rontani, C. The alveolar macrophage: the Trojan horse of Bacillus anthracis. Trends Microbiol. 10, 405-409 (2002) WEB SITE

Michael Karin's lab:

http://medicine.ucsd.edu/pharmaco/mkarin.html

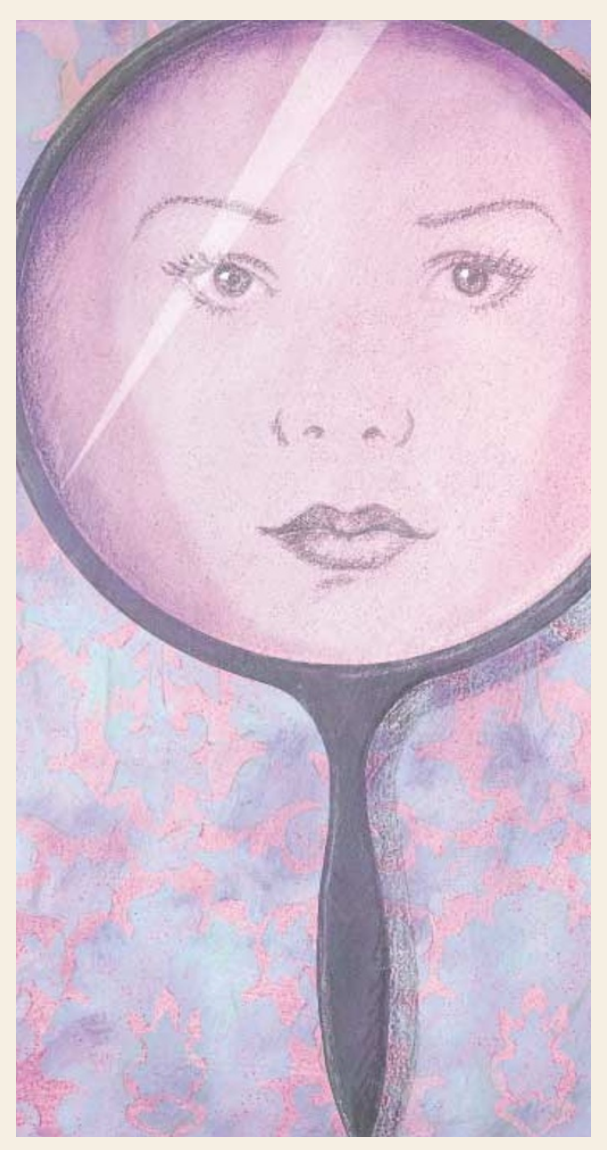

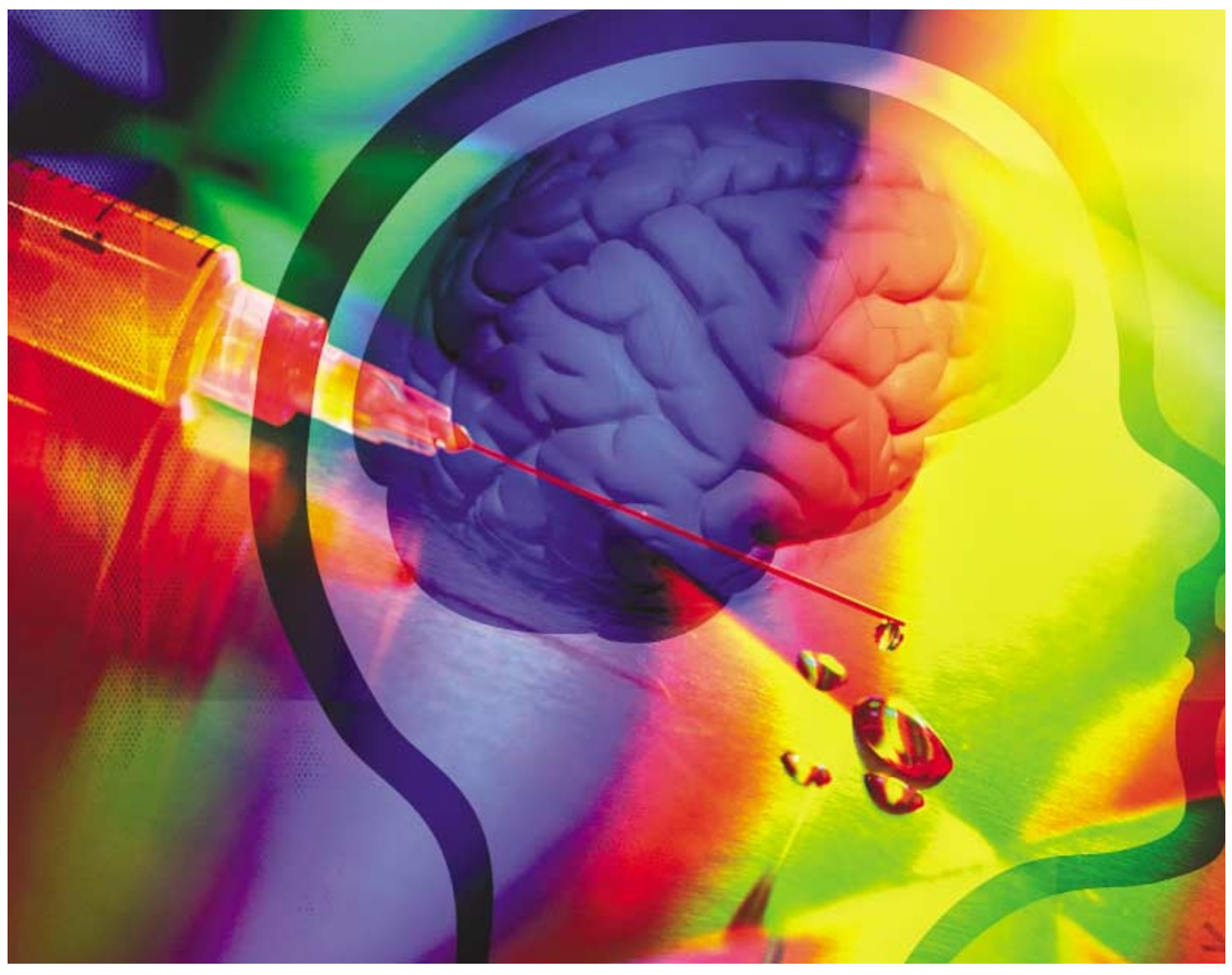

VACCINES

\title{
Vaccine revisited
}

Earlier this year, Elan Pharmaceuticals and Wyeth-Ayerst were forced to halt Phase II studies of their vaccine for Alzheimer's disease after the discovery that 15 patients had developed severe brain inflammation. The vaccine - a fragment of amyloid precursor protein (APP) known as $\mathrm{A} \beta_{42}$, which stimulates a response to the $\beta$-amyloid plaques that are a hallmark of the disease - had shown highly promising results in preclinical models and Phase I trials.

Two studies in Nature Medicine now indicate that there could still be hope for this strategy after all. Nitsch and colleagues detected a positive antibody response in a subset of patients who took part in the ill-fated trial, and McLaurin and colleagues show that refining the epitope might eliminate the side effects.

Nitsch and colleagues found that serum antibodies from most patients treated with the vaccine plus booster recognized $\beta$-amyloid plaques, diffuse $A \beta$ deposits and vascular $\beta$-amyloid in the brain blood vessels of transgenic mice bred to develop marked Alzheimer's-like $\beta$-amyloid deposits. Importantly, the antibodies did not cross-react with APP, which is found in the nerve cells of both healthy subjects and patients with Alzheimer's disease. In other words, the vaccine selectively induced the desired immune response against disease-associated forms of $\mathrm{A} \beta$ - whether it can prevent cognitive decline will be the focus of future studies.

The study by McLaurin and colleagues assessed whether the beneficial effects of the vaccine could be separated from the inflammatory side effects. Mass spectrometry showed that therapeutic antibodies raised against $A \beta_{42}$ recognized an epitope defined by residues 4 to 10 (termed $\mathrm{A} \beta_{4-10}$ ). Incubating serum that contains antibodies raised against $A \beta_{42}$ with cells was used to show that these antibodies can inhibit both the generation of fibrils (the long thread-like aggregates of misfolded proteins that are associated with the formation of amyloid plaques) and cytotoxicity. When the immune response that is induced by $A \beta_{4-10}$ was assessed in mice, the researchers found that $A \beta_{4-10}$ stimulates a Thelper $2\left(\mathrm{~T}_{\mathrm{H}} 2\right)$ response and the production of anti-A $\beta_{4-10}$ antibodies. But, $\mathrm{T}_{\mathrm{H}} 1$ responses, which many speculate were the cause of the adverse side effects in the clincial trial, were not detected.

These results indicate that a more refined vaccine, based on $A \beta_{4-10}$, might be effective and safe in humans. And, intriguingly, a clearer understanding of the antibody-antigen interactions might lead also to the generation of small-molecule drugs that mimic the effects of the vaccine.

Associate Editor (News), Nature Reviews Drug Discovery

(2) References and links

ORIGINAL RESEARCH PAPERS Hock, C. et al. Generation of antibodies specific for $\beta$-amyloid by vaccination of patients with Alzheimer disease. Nature Med. 15 October 2002

(DOI 10.1038/nm783) | McLaurin, J. et al. Therapeutically effective antibodies against amyloid- $\beta$ peptide target amyloid- $\beta$ residues $4-10$ and inhibit cytotoxicity and fibrillogenesis. Nature Med. 15 October 2002 (DOI 10.1038/nm790)

FURTHER READING Schenk, D. Amyloid- $\beta$ immunotherapy for Alzheimer's disease: the end of the beginning. Nature Rev. Neurosci. 3, 824-828 (2002) 